\title{
A NANOTECNOLOGIA NO BRASIL E O DESENVOLVIMENTO DE PRODUTOS COM ATIVIDADE ANTIMICROBIANA
}

\author{
Bruna de Paula Diasa, Erica Milena de Castro Ribeiroa, Ricardo Lemes Gonçalves ${ }^{\mathrm{a}}$, Diego Santos Oliveira ${ }^{\mathrm{b}}$, Tiago Hilário \\ Ferreira $^{\mathrm{b}}$ e Breno de Mello Silva ${ }^{\mathrm{a}, *, \text {, }}$ \\ aDepartamento de Ciências Exatas e Biológicas, Universidade Federal de Ouro Preto, 35400-000 Ouro Preto - MG, Brasil \\ 'INNOMA - Innovative Materials, 31270-150 Belo Horizonte - MG, Brasil \\ Recebido em 13/09/2020; aceito em 02/03/2021; publicado na web em 24/03/2021
}

\begin{abstract}
NANOTECHNOLOGY IN BRAZIL AND THE DEVELOPMENT OF PRODUCTS WITH ANTIMICROBIAL ACTIVITY. Due to the tremendous technological potential and applicability in various industry branches, nanotechnology investments have been increasing over the years. In particular, the control of microorganisms using nanomaterials with antimicrobial action has aroused great interest in the industry. This control makes it necessary in the most diverse situations, such as food conservation, pharmaceutical industry, hospital environments, and even domestic and commercial environments. This extraordinary interest is due, in particular, to the physical-chemical characteristics of materials on a nanoscale that attributes greater efficiency in combating microorganisms. Therefore, researchers and entrepreneurs have directed investments and efforts towards developing new products and/or new applications for antimicrobial products already existing on the market. In this work, we made a brief presentation of the history of nanotechnology in Brazil with a focus on Brazilian companies that developed products or services with nanomaterials with antimicrobial action, and on the description of some of the existing applications in the Brazilian market, highlighting the productive potential of the parents.
\end{abstract}

Keywords: nanotechnology; antimicrobials; innovation.

\section{INTRODUÇÃO}

A nanotecnologia é reconhecida como uma tecnologia capaz de manipular a matéria em escala nanométrica (um bilionésimo de metro). ${ }^{1}$ Mesmo que o seu uso seja desde 4.000 anos a.C., ${ }^{2}$ com o emprego da suspensão nanoparticulada de ouro como "elixir da longa vida", o precursor da nanotecnologia foi Richard Phillips Feynman que, no ano de 1959, em sua palestra intitulada "There's plenty of room at the bottom", sugeriu ser possível a manipulação e controle de átomos em escala nanométrica. Segundo Feynman, a disposição dos átomos um a um na forma desejada permitiria a criação de novas estruturas ou a modificação de estruturas já existente. ${ }^{3}$ Anos depois, em 1974, o termo nanotecnologia foi criado pelo professor Norio Taniguchi, da Universidade de Ciências de Tóquio. ${ }^{4}$

Atualmente, diferentes agências regulatórias internacionais definem nanomateriais com base em sua função, forma, carga, proporção da área superficial, volume ou outras propriedades físicas ou químicas. ${ }^{5,6} \mathrm{O}$ International Organization for Standardisation (ISO), na ISO/TC 229, estabelece como nanomaterial o material com qualquer dimensão externa ou estrutura interna e de superfície entre 1-100nm. ${ }^{7}$ A Comissão Europeia propõe como nanomaterial um composto que tem em sua constituição $50 \%$ ou mais de partículas compreendidas entre $1 \mathrm{~nm}$ e $100 \mathrm{~nm}$ e, em casos específicos, o limiar da distribuição número-tamanho pode ser substituído por um limiar compreendido entre 1 e 50\%. ${ }^{8}$ Independente dessas definições, é um consenso que nem toda estrutura com dimensões externas inferiores a $100 \mathrm{~nm}$ pode ser considerada nanomaterial. Para isso, as propriedades físico-químicas precisam ser diferenciadas das que o material possui em escalas maiores. ${ }^{6}$ Por apresentarem essas alterações em diversas propriedades físicas, tais como condutividade elétrica, reatividade, ponto de fusão, ópticas, dentre outras, ${ }^{9,10}$ é que os nanomateriais se tornam tão interessantes.

*e-mail: breno@ufop.edu.br
Diante da necessidade de geração de novos produtos, a implementação da nanotecnologia tornou-se estratégica para o desempenho econômico das nações. ${ }^{1,11}$ Estima-se que, atualmente, mais de 12 mil empresas de 53 países empreguem nanotecnologia em seus produtos, bem como o faturamento global destas empresas para 2020 seja de aproximadamente 3 trilhões de dólares americanos..$^{11} \mathrm{O}$ Brasil dispõe de investimentos públicos e privados que permitem a criação de programas, redes cooperativas de pesquisa e laboratórios de apoio ao desenvolvimento de pesquisa em universidades, institutos de pesquisas e empresas.

A nanotecnologia é um domínio multidisciplinar com muitas aplicações em nosso cotidiano., ${ }^{412}$ Dentre elas, o uso de nanomateriais com propriedades antimicrobianas ganha destaque em virtude da necessidade de desenvolver novos meios para combater microrganismos resistentes e ao reforço dos hábitos de higiene pessoal da população no contexto da pandemia de COVID-19. ${ }^{13,14}$ A resistência aos antimicrobianos é uma das principais ameaças a saúde pública global em razão da diminuição da eficácia dos fármacos frente as infecções, promovendo o aumento da mortalidade, dos riscos dos procedimentos médicos e os custos com a saúde..$^{15}$ Diante disso, é crucial o desenvolvimento de novos agentes com diferentes de mecanismos de ação em relação aos fármacos em uso, e a nanotecnologia se mostra promissora para este propósito. A atividade antimicrobiana das nanopartículas está relacionada com a sua capacidade de interagir com a membrana celular das bactérias, de inativar o processos de replicação do DNA, de geração de espécies reativas de oxigênio que resulta na inibição de funções enzimáticas; do rompimento da membrana celular de fungos e do bloqueio da ligação viral à superfície da célula. ${ }^{13,16-18}$ Por apresentarem um conjunto diversificado de mecanismos de ação, a obtenção de resistência às nanopartículas pelos microrganismos torna-se muito difícil. ${ }^{13,18}$ As formulações de antibióticos em escala nanométrica têm mostrado melhor eficácia que os fármacos convencionais por possibilitarem a entrega direcionada do fármaco 
aos locais de infecção e liberação do composto de forma continuada e controlada. ${ }^{19-21}$

Em razão do grande potencial tecnológico, pesquisadores e empreendedores têm aplicado a nanotecnologia no desenvolvimento e no aprimoramento de produtos de consumo para conferir-lhes novas funções e características.

\section{UM BREVE HISTÓRICO DA NANOTECNOLOGIA NO BRASIL}

A partir da década de 1990, as primeiras empresas a utilizarem nanotecnologia começaram a atuar entre os anos de 1999 e 2000, quando os primeiros produtos de consumo nanotecnológicos começaram a surgir no mercado. ${ }^{22}$ Nos anos 2000 e 2001, a nanotecnologia ganhou notoriedade mundial com o lançamento dos programas "National Nanotecnology Initiative" pelo Estados Unidos, a criação do Comitê Nacional para Nanociência e Nanotecnologia e do programa "National Nanotechnology Development Strategy 2001-2010" pela China. ${ }^{12,23,24}$

No Brasil, o primeiro edital específico sobre nanociência e nanotecnologia foi lançado em 2001 e incitou a formação de quatro Redes Cooperativas de Pesquisa: Materiais Nanoestruturados, sediada na Universidade Federal do Rio Grande do Sul (UFTGS); Nanotecnologia Molecular e de Interfaces sediada na Universidade Federal de Pernambuco (UFP), Nanodispositivos Semicondutores e Materiais Nanoestrutrados também sediada na UFP; e Nanobiotecnologia, sediada na Universidade Estadual de Campinas (UNICAMP) (Figura 1).,12 Cabe ressaltar que, antes desse período, algumas pesquisas já eram realizadas na área de nanotecnologia no país. ${ }^{12,23}$

Em 2003, foi criada a Coordenação-Geral de Políticas e Programas de Nanotecnologia, atualmente denominada Coordenação de Micro e de Nanotecnologias (CGNT) e foi criado o Grupo de Trabalho (GT) pela Portaria $\mathrm{MCT}^{\circ}$ 252, de 16.05.2003, para elaborar a proposta do Programa de Desenvolvimento da Nanociência e Nanotecnologia. ${ }^{23,25}$ No ano de 2004, foi lançado no âmbito do Plano Plurianual (PPA) 2004-2007, o Programa 1110 - Desenvolvimento da Nanociência e da Nanotecnologia; ${ }^{12,23}$ foi criado o GT para estudo sobre a implantação do Laboratório Nacional de Micro e Nanotecnologia; foi criada a Ação Transversal de Nanotecnologia nos Fundos Setoriais; e foi instituída a Rede BrasilNano pela portaria ${ }^{\circ} 614$, de $1^{\circ}$ de dezembro de 2004. ${ }^{23,26}$

Em 2005, foram designados os membros do Conselho Diretor da Rede BrasilNano e o Programa 1110 foi inserido em um outro programa, o Programa 1388 - Ciência, Tecnologia e Inovação para a Política Industrial, Tecnológica e de Comércio Exterior (PITCE). ${ }^{27}$ Nesse mesmo ano, foi lançado o Programa Nacional de Nanotecnologia (PNN) e assinado o Protocolo de Estabelecimento do Centro Brasileiro-Argentino de Nanotecnologia (CBAN), com o objetivo de executar projetos conjuntos de pesquisa e desenvolvimento, formação e capacitação de recursos humanos científicos nestes dois países. ${ }^{1,12,23,28}$

Em 2007, foi lançado o Plano de Ação em Ciência, Tecnologia e Inovação (PACTI) 2007-2010, com a finalidade de coordenar as competências e ações de todo o Governo Federal em cooperação com os governos estaduais, distrital e municipais e outros membros. ${ }^{29}$

Em março de 2008, foi inaugurada uma unidade de pesquisa avançada, o Centro de Nanociência e Nanotecnologia Cesar Lattes - C2Nano, vinculado ao Laboratório Nacional de Luz Síncrotron (LNLS). ${ }^{30}$ Em maio desse mesmo ano foi lançado pelo Governo Federal a Política de Desenvolvimento Produtivo (PDP) integrada ao Programa Mobilizador em Nanotecnologia, cuja gestão ficou a cargo do Ministério de Ciência, Tecnologia e Inovação, hoje o Ministério de Ciência, Tecnologia e Inovação e Comunicações - MCTIC. ${ }^{23}$ Em julho, foi instituído o Programa Institutos Nacionais de Ciência e Tecnologia (INCTs), pela Portaria MCT No 429, 17.07.2008. ${ }^{31}$ Os INCTs são redes de pesquisas em áreas estratégicas que contam com 101 institutos, sendo 10 institutos voltados para área da nanotecnologia sediados em diferentes regiões do país. O intuito dos INCTs é desenvolver pesquisas de alto impacto científico, impulsionar a competitividade internacional e estimular a inovação e o espírito empreendedor no país. ${ }^{32}$ As atividades desempenhadas pelos pesquisadores dos INCTs de nanotecnologia proporcionaram o desenvolvimento de novos projetos, produção científica e fortalecimento no diálogo e parceria entre empresas e os institutos. ${ }^{33,34}$

Iniciado em 2009, o Fórum de Competitividade de Nanotecnologia surgiu como ferramenta estratégica para alinhar os interesses em nanotecnologia de empresas, governo e pesquisadores..$^{35}$

O MCTIC criou, em 2012, o SisNano (Sistema Nacional de Laboratórios em Nanotecnologias), ${ }^{1}$ um sistema de laboratórios multiusuário e de acesso aberto que tem como objetivo o fornecimento de infraestrutura adequada para ajudar pesquisadores, órgãos públicos e companhias no desenvolvimento de projetos na área de nanotecnologia. Na primeira fase do SisNano (2013-2018), vinte e seis laboratórios integravam o programa, 203 projetos foram desenvolvidos em parceria entre os setores público e privado; 122 projetos em parceria com instituições e empresas internacionais; 105 bolsas de pesquisa foram concedidas por ano; 180 pedidos de patentes envolvendo nanotecnologias pelas instituições integrantes do SisNANO foram depositadas desde o início do Programa; houve a participação dos representantes dos laboratório em cerca de 380 eventos; aproximadamente 300 equipamentos foram adquiridos com recursos de capital disponibilizados no âmbito do programa; e cerca de R \$ 6 milhões foram arrecadados por meio da prestação de serviços..$^{36,37}$ Para a integração da segunda fase do programa, o SisNANO 2.0, foi aberta Chamada Pública (CNPq/MCTIC n 18/2019) em 2019, a qual previa a destinação de $\mathrm{R} \$ 6$ milhões entre os anos de 2019 a 2023 para os laboratórios, podendo ainda haver a complementação de recursos por parte do MCTIC e de parcerias externas. ${ }^{38}$ Foram selecionados vinte e três laboratórios para a segunda fase. Ainda em 2019, por meio da Portaria $\mathrm{n}^{\circ} 2.376$, de 16 de maio de 2019, o SisNANO foi incluído como um dos eixos estratégicos da Iniciativa Brasileira de Nanotecnologia (IBN). ${ }^{39}$

Também em 2012 foi publicada a Portaria 117 do Centro BrasilChina de Pesquisa e Inovação em Nanotecnologia (CBCIN) com o objetivo de coordenar as atividades envolvendo a cooperação BrasilChina em áreas de nanotecnologia e até o momento, foram firmados 10 projetos conjuntos entre instituições desses dois países. ${ }^{1}$ Ainda nesse ano, foi criado o Comitê Interministerial de Nanotecnologia (CIN) com o intuito de auxiliar os ministérios na gestão das ações desenvolvidas no país voltadas para nanotecnologia. ${ }^{40}$

Com a atuação em conjunto dos diferentes Ministérios do Brasil, Conselho Nacional de Desenvolvimento Científico e Tecnológico (CNPq), Centro de Gestão e Estudos Estratégicos, a Financiadora de Estudos e Projetos e o Banco Nacional de Desenvolvimento Econômico e Social (BNDES), foi lançada em 2013 a IBN, um importante programa de política pública que uni ações governamentais em nanotecnologia direcionadas para a inovação da indústria brasileira e para o desenvolvimento econômico e social. ${ }^{1}$ No ano de 2019, a IBN foi firmada como principal programa estratégico para incentivo da nanotecnologia no país pela Portaria $n^{\circ} 3.459$, de 26 de julho de $2019 .{ }^{41}$

Em 2014, o Brasil aderiu ao programa NANoREG (A common European approach to the regulatory testing of Manufactured Nanomaterials), programa financiado pela União Europeia, que teve a finalidade de propor uma regulamentação da nanotecnologia e seus produtos. ${ }^{1}$ A inserção do Brasil nesse programa foi essencial para o 
estabelecimento de um marco regulatório para nanotecnologias e, através dessa colaboração, metodologias cientificamente referenciadas para avaliação da segurança de nanomateriais foram possíveis de serem definidas. ${ }^{42}$ Com base nos protocolos desenvolvidos nesse programa e a colaboração dos Laboratórios do Programa SisNANO, em 2017 foi iniciado o projeto para estabelecimento de procedimentos para certificação de produtos oriundos da nanotecnologia. Esse projeto está sob a gestão científica do corpo técnico do INMETRO e a previsão para conclusão é em $2021 .^{1}$

O Ministro do MCTIC, em 2018, institui o Comitê Consultivo de Nanotecnologia e Novos Materiais (CCNANOMAT), pela Portaria MCTIC $\mathrm{n}^{\circ}$ 324, de 17.01.2018. De acordo com a portaria, o CCNANOMAT foi instituído para assessorar o MCTIC na definição dos macros objetivos, áreas prioritárias, diretrizes, alocação de recursos, avaliação das iniciativas, ações, programas e projetos nas áreas de nanotecnologia e novos materiais. ${ }^{43}$ Nesse mesmo ano, foi inaugurado o Sirius, uma fonte de luz sincrotron de quarta geração, instalado no campus do Centro Nacional de Pesquisa em Energia e Materiais (CNPEM). Esse é considerado o maior projeto da ciência brasileira e é o maior acelerador de partículas de luz síncroton do mundo. ${ }^{44}$ Conforme o CNPEM, o Sirius é uma importante ferramenta que possibilitará novas perspectivas de pesquisa no país em diferentes áreas do conhecimento. ${ }^{45}$ Ainda em 2018, o MCTIC lançou o Plano de Ação de Tecnologias Convergentes e Habilitadoras, estabelecendo estratégias para o desenvolvimento da nanotecnologia no Brasil. ${ }^{46}$

Em 2020, foi aprovado pela Comissão de Constituição e Justiça (CCJ) o Marco Legal da Nanotecnologia e Materiais Avançados (PL 880/2019), seguindo para análise na Comissão de Ciência e Tecnologia (CCT). A PL 880/2019 busca incentivar a pesquisa, o desenvolvimento científico, inovação e capacitação relacionados a área da nanotecnologia. ${ }^{47}$

A nanotecnologia é mantida como o alvo de investimentos do poder público no Brasil, com investimentos no PPA de 20202023 e conta com apoio de fundações e empresas, como o CNPq, Coordenação de Aperfeiçoamento de Pessoal de Nível Superior (CAPES), as FAPs, Financiadora de Estudos e Projetos (FINEP),
Embrapii, Sibratec, Nanotechnology Innovation Cluster (API.nano) e BNDES. ${ }^{1,48}$

Nos últimos 15 anos, cerca de R\$ 600 milhões dos recursos públicos foram investidos em nanotecnologia, valores muito inferiores quando comparados ao investimento mundial. ${ }^{40}$ No Projeto de Lei Orçamentária Anual 2020 (PLOA2020), o orçamento previsto para nanotecnologia é de $\mathrm{R} \$ 2.200 .000,00$ com a estimativa de chegar a $\mathrm{R} \$ 2.800 .000,00$ até o final do ano. ${ }^{49}$

\section{NANOPARTÍCULAS COMO AGENTES ANTIMICROBIANOS NO MERCADO BRASILEIRO}

O aumento de casos de infecções causadas por microrganismos resistentes a fármacos ocasiona o aumento da mortalidade, dos riscos dos procedimentos médicos e os custos com a saúde. O que justifica o desenvolvimento novos compostos ou a modificação dos compostos já disponíveis. ${ }^{13,15}$ Além disso, o reforço dos hábitos de higiene em tempos de pandemia, aumentou a demanda por produtos antimicrobianos para diminuir a disseminação de microrganismos e prover a sensação de segurança e bem-estar aos consumidores. Atualmente o mercado oferece produtos com aditivos antimicrobianos para os ambientes hospitalar, industrial e doméstico. A perspectiva de crescimento do mercado têxtil para 2025, por exemplo, é de 3,3 bilhões de dólares,${ }^{50}$ e no mercado de plástico antimicrobiano (aplicados em embalagens, automotivo, bens de consumo, medicina e saúde, construção e outros) a estimativa de investimento é de 22,9 bilhões de dólares até $2025 .^{51}$

A busca por novos compostos para combater microrganismos resistentes envolve também a utilização de nanopartículas, pois, a ação antimicrobiana das nanopartículas pode ocorrer por mecanismos diversificados. Algumas nanopartículas inorgânicas (metais e óxidos metálicos) criam aberturas na membrana que resultam na morte celular. Ou ainda, permite que as nanopartículas atravessem a parede celular e a membrana citoplasmática para o citoplasma da célula bacteriana onde exercem outros efeitos antimicrobianos..$^{13,16} \mathrm{As}$ nanopartículas também podem interagir com o DNA cromossomal

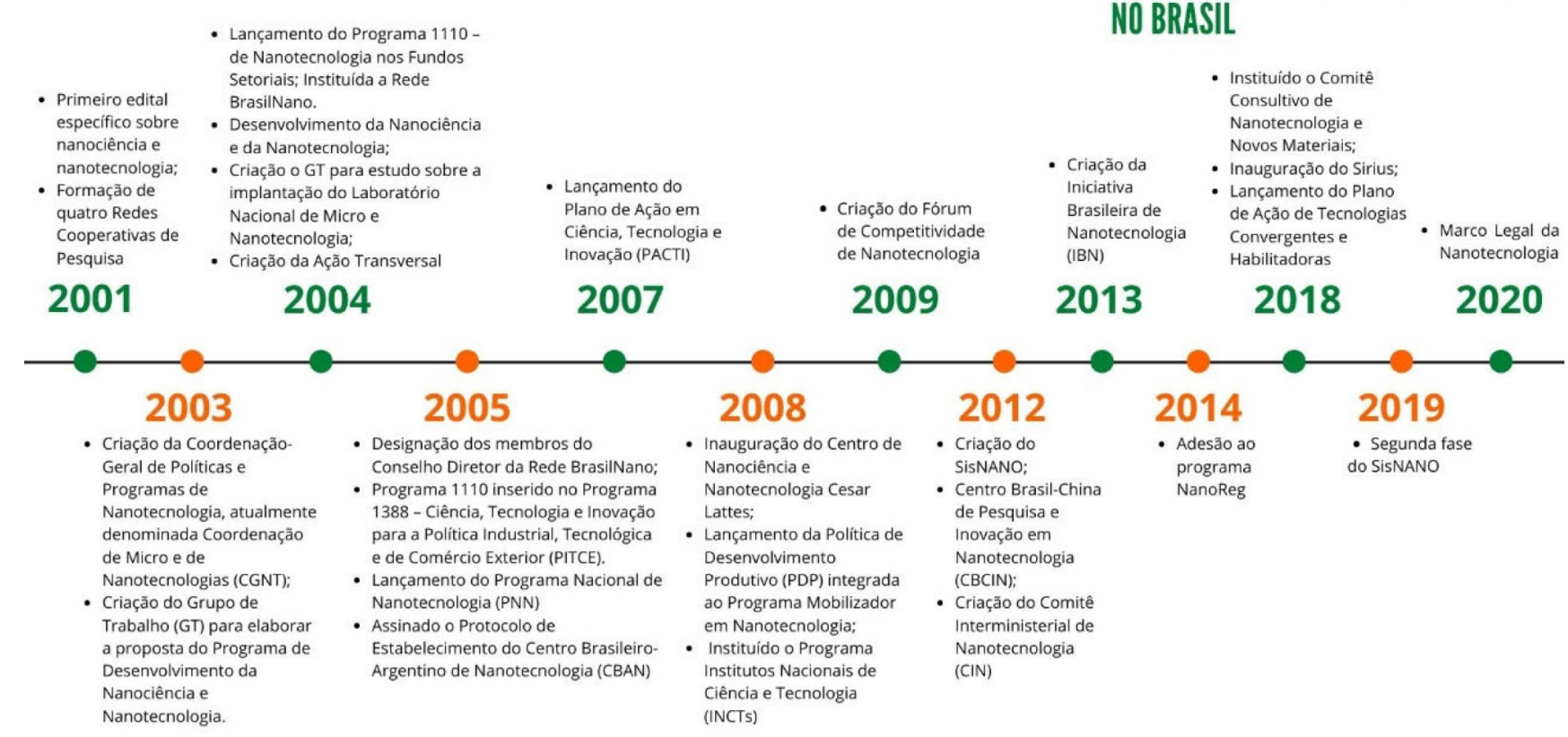

BREVE HISTÓRICO DA NANOTECNOLOGIA NO BRASIL de Nanotecnologia Setoriais; Instituída a Rede BrasilNano. específico

nanotecnologia; - Criação o GT para estudo sobre Cooperativas de acional de Micro anotecnologia; Pesquisa ão Transversal Ciênci de Aça en ação (PACT)
Criação da

Brasileira de

Nanotecnologia nologia

Figura 1. Infográfico representando marcos da história da nanotecnologia no Brasil em ordem cronológica 
e prejudicar o processo de replicação do DNA bacteriano, ou ainda gerar espécies reativas de oxigênio que resultam na inibição de funções enzimáticas. ${ }^{13,16,52,53}$ Além disso, podem causar a ruptura da membrana celular de fungos e o bloqueio da ligação viral à superfície celular. ${ }^{15}$ Em relação as nanopartículas orgânicas, a ação antimicrobiana pode estar relacionada com a liberação de antibióticos, peptídeos antimicrobianos e agentes antimicrobianos ou pela eliminação por contato de superfícies catiônicas. ${ }^{53} \mathrm{~A}$ eficácia das nanopartículas é dependente do tipo de material utilizado bem como o tamanho, morfologia, carga elétrica, revestimentos de superfícies etc, ${ }^{16,18,54}$ o que permite a criação de diferentes composições com ação antimicrobiana para diferentes microrganismos e para diferentes fins além da aplicação terapêutica. Em virtude do seu tamanho reduzido e grande área superficial em relação ao volume, o que garante maior interação do nanomaterial com o ambiente circundante e pode conferir maior atividade antimicrobiana. ${ }^{18}$ Em relação aos antibióticos convencionais, as nanopartículas são vantajosas devido ao improvável desenvolvimento de resistência, a redução de custos e o simples preparo. ${ }^{54}$

Diante do enorme potencial para geração de produtos, diversas empresas no país descobriram na nanotecnologia uma oportunidade de negócio para inovar e elevar o valor agregado de seus produtos e serviços (Tabela 1).

Pioneira na área da nanotecnologia, a Nanox é uma empresa

Tabela 1. Produtos de empresas brasileiras que contêm em sua composição nanopartículas antimicrobianas

\begin{tabular}{cl}
\hline Nome da empresa e localidade (cidade/estado) & Produtos \\
& Nanoaditivos antimicrobianos. \\
NANOX & Bebedouros de aço inoxidável e plástico da empresa IBBL, revestimento industrial da Con- \\
crekor, tapetes e carpetes da Tapetes São Carlos, embalagens da AlpFilm, secadores de cabelo & e em chapas de alisamento da Taiff, equipamentos odontológicos da Dabi Atlante, brinquedos \\
(São Carlos, SP) & e máscaras eda Odontopet, fabricação de ductos de ar pela Plascar, garrafa térmica da Termolar
\end{tabular}

\begin{tabular}{|c|c|}
\hline $\begin{array}{l}\text { TNS Solution } \\
\text { (Florianópolis, SC) }\end{array}$ & $\begin{array}{l}\text { Nanoaditivos antimicrobianos. } \\
\text { Formulação do esmalte das panelas Linea da empresa Oxford Porcelanas, utensílios de cozinha } \\
\text { da Yuze, carpetes da SGI Beauliei do Brasil, acrílico da Bold }\end{array}$ \\
\hline $\begin{array}{l}\text { Nanovetores Group } \\
\text { (Florianópolis, SC) }\end{array}$ & $\begin{array}{l}\text { Nano e microencapsulação. } \\
\text { Ativo Nano Fungi (antifúngico) e Nano Bioprotect (antimicrobiano). }\end{array}$ \\
\hline $\begin{array}{l}\text { Podal Nano Cosméticos } \\
\text { (Loja online) }\end{array}$ & $\begin{array}{l}\text { Formulação com nanotecnologia e biotecnologia para cosméticos. } \\
\text { Fungi Mai: antifúngico nanoencapsulado. }\end{array}$ \\
\hline $\begin{array}{c}\text { Doce erva } \\
\text { (Ribeirão Preto, } S P)\end{array}$ & $\begin{array}{l}\text { Formulação de óleos essenciais nanoparticulados para unhas. } \\
\text { Nano Nails: óleos essenciais de capim-limão, melaleuca e cravo nanoparticulado. }\end{array}$ \\
\hline $\begin{array}{l}\text { NanoScoping } \\
\text { (Florianópolis, SC) }\end{array}$ & $\begin{array}{l}\text { Nanoinsumos veterinários. } \\
\text { Nano Melaleuca (antimicrobiano), Nano Fitoesfingosina (antimicrobiano) Nano Calêndula } \\
\text { (antisséptico). }\end{array}$ \\
\hline $\begin{array}{c}\text { Nanoita } \\
\text { (Ponta Grossa, PR) }\end{array}$ & Revestimento de cerâmica antimicrobiana nanoestruturada. \\
\hline $\begin{array}{l}\text { Innoma Innovative Materials } \\
\quad(\text { Belo Horizonte, } M G)\end{array}$ & Nanoativos antimicrobianos de nanopartículas de prata. \\
\hline $\begin{array}{c}\text { NanoTropic } \\
\text { (Curitiba, } P R \text { ) }\end{array}$ & Nanoativos antimicrobianos da linha TropiCare \\
\hline $\begin{array}{l}\text { Nanowear Nanotecnologia } \\
\quad \text { (Novo Hamburgo, RS) }\end{array}$ & Produtos têxtil com nanopartículas antimicrobianas. \\
\hline $\begin{array}{l}\text { Santista têxtil } \\
\text { (vendida para Siete Leguas) } \\
\text { (São Paulo, SP) }\end{array}$ & Tecidos com nanopartículas antimicrobianos da linha NanoComfort. \\
\hline $\begin{array}{c}\text { WEG } \\
\text { (Jaraguá do Sul, SC) }\end{array}$ & $\begin{array}{l}\text { Tomadas e interruptores com nanopartículas antimicrobianas, da linha Composé, produtos } \\
\text { NobaC. }\end{array}$ \\
\hline $\begin{array}{l}\text { Suzano Petroquímica } \\
\text { (vendida para Petrobras) }\end{array}$ & $\begin{array}{l}\text { Resina especial de polipropileno nanoestruturado com partículas de prata. } \\
\text { Colchões, tábuas de carne e, em parceria com a empresa Suggar (também brasileira), fabri- } \\
\text { caram máquina de lavar. }\end{array}$ \\
\hline $\begin{array}{l}\text { Itabanyl Produtos Especiais (Ipel) } \\
\text { (vendida para Lanxess) (Jarinu, SP) }\end{array}$ & Linha de antimicrobianos com tecnologia AgNano que utiliza nanopartículas de prata. \\
\hline $\begin{array}{l}\text { Laza Biotecnologia } \\
\quad(\text { Xanxerê, } S C)\end{array}$ & Sanitizantes em aerossol que contém nanopartículas antimicrobianas da linha FULLCLEAN. \\
\hline $\begin{array}{c}\text { Promaflex } \\
\text { (Taboão da Serra, SP) }\end{array}$ & Manta adesiva com nanopartículas de prata com propriedades antimofo. \\
\hline $\begin{array}{c}\text { Equinox } \\
\text { (Rio de Janeiro, RJ) }\end{array}$ & Camiseta ION LITE ${ }^{\mathrm{TM}}$ com nanopartículas de prata para controle da proliferação de bactérias. \\
\hline $\begin{array}{l}\text { Insider Store } \\
\text { (São Paulo, SP) }\end{array}$ & Camiseta e máscara antiviral e bactericida que usam nanotecnologia na fabricação. \\
\hline $\begin{array}{l}\text { Dublauto Gaúcha } \\
\text { (Campo Bom, RS) }\end{array}$ & Palmilha Sequinha com nanopartículas de prata antimicrobiana. \\
\hline
\end{tabular}


que surgiu em 2004 com um grupo de colegas da Pós-graduação do Instituto de Química, da Unesp de Araraquara, para a formação de uma startup. ${ }^{55}$ Com apoio inicial da FAPESP e da incubadora ParqTec, a Nanox hoje é líder no mercado nacional, exportando para os países como México, Colômbia, Chile, Paquistão e Argentina, e conta com uma filial no estado de Massachusetts, nos Estados Unidos. A NanoxClean é a principal linha de produtos da empresa e tem a capacidade de reduzir o potencial de contaminação microbiana atuando no controle microbiológico por meio das superfícies ativas dos materiais tratados. As formulações podem ser empregadas em diferentes materiais. Entre os produtos comercializados que utilizam a tecnologia da Nanox, há os bebedouros de aço inoxidável e plástico da empresa IBBL, ${ }^{55}$ revestimento industrial da Concrekor, ${ }^{55}$ tapetes e carpetes da Tapetes São Carlos, ${ }^{55}$ embalagens da AlpFilm, ${ }^{56}$ secadores de cabelo e chapas de alisamento da Taiff, ${ }^{57}$ equipamentos odontológicos da Dabi Atlante, ${ }^{58}$ brinquedos para cães da marca Odontopet, ${ }^{59}$ dutos de ar da empresa Plascar, ${ }^{60}$ garrafa térmica da Termolar. ${ }^{61}$ Em decorrência da necessidade da utilização de máscaras no enfrentamento a pandemia de COVID-19, a Nanox e a indústria Elka desenvolveram uma máscara respiratória reutilizável feita com a linha NanoxClean. ${ }^{62}$

Outro sucesso é a TNS Solution, ${ }^{63,64}$ criada por químicos e engenheiros da Universidade Federal de Santa Catarina no ano de 2009. A empresa produz aditivos antimicrobianos à base de nanopartículas de prata para serem incorporadas a diversos produtos, com destaque para os segmentos têxtil, polímeros, tintas, agronegócio, médico hospitalar e cerâmicos. Recentemente, a TNS desenvolveu o TNS PROTEC-20, ${ }^{65}$ uma formulação de nanopartículas que atua como antiviral e auxilia a inibição e replicação de bactérias. As soluções antimicrobianas da TNS já foram inseridas na formulação do esmalte que cobre as panelas Linea da empresa Oxford Porcelanas, ${ }^{66} \mathrm{em}$ utensílios de cozinha da empresa Yuze,${ }^{67}$ em carpetes da empresa SGI Beaulieu do Brasil, ${ }^{63}$ em acrílico da empresa Bold e conta com parceria de outras grandes empresas. ${ }^{68}$ Selecionados no Edital de Inovação para a Indústria na categoria Missão Covid-19, a TNS está desenvolvendo um revestimento antiviral aplicado por meio de spray para ajudar no combate a Covid-19. O revestimento é baseado em nanopartículas de prata e a expectativa é de que seu uso reduzirá a capacidade de transmissão do vírus. Em razão da facilidade de aplicação, o produto poderá ser utilizado em superfícies como maçanetas de portas, mesas, entre outros. O desenvolvimento do spray será realizado em parceria com o Instituto SENAI. ${ }^{69}$

A Nanovetores Group é uma empresa multinacional brasileira reconhecida mundialmente pelo desenvolvimento de sistemas de nano e microencapsulação de ativos. ${ }^{70}$ Entre seus produtos antimicrobianos estão o ativo Nano Bioprotect, que possui propriedades antissépticas e desinfetantes e o ativo Nano Fungi, ${ }^{71}$ um antifúngico que contém óleos essenciais encapsulados em nanopartículas lipídicas. A empresa aposta em seus ativos para o cuidado das mãos durante a pandemia de Covid-19. ${ }^{72}$ Com a maior frequência de higienização necessária das mãos com álcool, a pele resseca e uma solução encontrada pela Nanovetores para evitar o ressecamento e ajudar na assepsia são os aditivos em cremes com dupla função, hidratante (NV Hydratech) e antisséptico (Nano Bioprotect).

Outra empresa no setor de cosméticos é a Podal Nano Cosméticos. ${ }^{73} \mathrm{~A}$ empresa trabalha com a utilização de nanotecnologia e biotecnologia na formulação de seus cosméticos. Em seu portfólio, o Fungi Mai atua como um antifúngico para unha, ${ }^{74}$ ele possui uma combinação de ativos, dentre eles: óleo de cravo, melaleuca, lavanda e copaíba, que são nanoencapsulados.

A Doce Erva, empresa que está há trinta e dois anos no mercado, aderiu a nanotecnologia em um de seus insumos. O produto Nano Nails é um insumo natural constituído por óleos essenciais de capim-limão, melaleuca e cravo nanoparticulado, conferindo propriedades antimicrobiana e antisséptica para ser utilizado nas unhas. ${ }^{75}$

Criada em 2014, a NanoScoping é uma empresa voltada para nanoinsumos veterinários. ${ }^{76}$ Os nanoinsumos podem ser adicionados em produtos de higiene e de cuidados de beleza e são desenvolvidos com tecnologia verde, a partir de ingredientes biocompatíveis e biodegradáveis. Entre os nanoinsumos, as fórmulas Nano Melaleuca e a Nano Fitoesfingosina possuem ação antimicrobiana e a fórmula Nano Calêndula possui ação antisséptica.

Já a empresa Nanoita é formada por pesquisadores da Universidade Estadual de Ponta Grossa (UEPG) e vinculada à Incubadora Tecnológica de Ponta Grossa (IntecPonta). Ela é responsável pela criação, produção e comercialização de cerâmicas de revestimento impregnadas com agentes bactericidas que utiliza tecnologias inovadoras a partir de nanoestruturas. ${ }^{77}$

A Innoma - Innovative Materials está no mercado desde 2016 e fornece nanopartículas de prata para serem incorporadas em produtos de tecnologias antimicrobianas. ${ }^{78} \mathrm{Com}$ desenvolvimento próprio e o domínio integral da propriedade intelectual (patente) do produto (Nanoativo de Prata), ${ }^{79}$ a empresa possui um modelo de produção outsourcing para um ativo antimicrobiano de alta eficiência, baixos custos operacionais e alta capacidade produtividade. Atualmente, a INNOMA comercializa seu primeiro produto em parceria com a EMFAL e está desenvolvendo nanoativos de cobre, zinco e ouro.

A NanoTropic é uma empresa que surgiu em 2015 e desenvolve e produz um nanoaditivo antimicrobiano. ${ }^{80} \mathrm{~A}$ linha de nanoativos desenvolvidos, TropiCare, pode ser adicionada em materiais, como plásticos, tintas, tecidos, revestimentos e podem ser usados para variados bens de consumo.

Situada na cidade de Novo Hamburgo no estado do Rio Grande do Sul, a Nanowear Nanotecnologia é uma empresa voltada para o setor têxtil com o desenvolvimento de produtos customizados com tecidos que usam nanotecnologia antimicrobiana ${ }^{81} \mathrm{O}$ produto Nanowear combate mais de 650 bactérias, fungos, ácaros e mofo. As tecnologias podem ser aplicadas em tecidos, como em roupas, uniformes, jalecos médicos, roupas de cama, mesa e banho etc.

Grandes empresas como a Santista têxtil (atualmente vendida para Siete Leguas) também integrou a nanotecnologia em seus produtos. A etiqueta "NanoComfort" traz ao tecido propriedades funcionais e dentre essas propriedades está a ação antimicrobiana. ${ }^{82} \mathrm{~A}$ empresa multinacional brasileira, WEG, inovou em seus produtos NobaC® da linha Composé, desenvolvendo tomadas e interruptores com proteção antimicrobiana utilizando a nanotecnologia. ${ }^{83}$ Segundo a empresa, esses produtos são ideais para ambientes hospitalares, escolares e demais locais que necessitam reduzir custos e riscos gerados por infecções ou contaminações cruzadas, causadas por microrganismos. A empresa Suzano Petroquímica (vendida para Petrobras em 2007) produziu produtos a partir de uma resina especial de polipropileno nanoestruturado com partículas de prata. Esse material possui sua ação bactericida e fungicida e vem sendo incorporado em diferentes produtos como colchões, tábuas de carne e, em parceria com a empresa Suggar (também brasileira), fabricando máquina de lavar. ${ }^{84}$

A multinacional brasileira Itabanyl Produtos Especiais (Ipel), vendida em dezembro de 2019 para a empresa alemã Lanxess, é especialista em controle microbiológico e conta em seu portfólio com uma linha de antimicrobianos que entre os diversos ingredientes ativos, tem incluído a tecnologia AgNano que utiliza nanopartículas de prata. Para a Ipel, os antimicrobianos possuem ação microbicida no filme seco e superfícies, o que permite agregar uma nova funcionalidade aos revestimentos. As formulações nanoparticuladas foram desenvolvidas em parceria com a Nanox. Entre as opções disponíveis, a AgNano 6012, além de sua ação bactericida, possui ação fungicida e algicida. ${ }^{85} \mathrm{~A}$ Laza 
Biotecnologia possui em seu catálogo os produtos FULLCLEAN, que são sanitizantes em aerossol que contêm nanopartículas e possuem eficiência na eliminação de microrganismos do ambiente. ${ }^{86}$ No segmento de filmes plásticos, a empresa Promaflex lançou uma manta adesiva com nanopartículas de prata com propriedades antimofo e bactericida para armários, gavetas, entre outros. ${ }^{87}$

A empresa brasileira Equinox, especializada na fabricação de produtos para atividades ao ar livre, especialmente o montanhismo e a escalada em rocha, também aderiu em seus produtos a nanotecnologia antimicrobiana. A camiseta ION LITETM ${ }^{\mathrm{TM}}$ conta em sua fabricação com nanopartículas de prata para o controle da proliferação de bactérias. ${ }^{88}$

A Insider Store, marca que produz undershirt e cueca tech, lançou em seu portfólio a camiseta e máscara antiviral e antimicrobiana. A $T$-shirt Antiviral é a primeira camiseta comprovadamente eficaz contra vírus e, entre a gama de vírus que a roupa busca prevenir, está o vírus da atual pandemia, o SARS-CoV-2. A tecnologia antiviral impede o tecido de ser meio de retenção e propagação de vírus e de bactérias pela sua rápida inativação. A máscara antiviral é produzida com o mesmo tecido da T-shirt Antiviral e auxilia na redução da transmissão do SARS-CoV-2. ${ }^{89}$

A Dublauto Gaúcha, empresa que atua no mercado têxtil e em componentes para calçados, conta com produtos antimicrobianos que têm um tratamento à base de nanopartículas de prata conferindo ao material tratado proteção contra o desenvolvimento de bactérias e fungos. ${ }^{90}$ Entre seus produtos, está a Palmilha Sequinha, ${ }^{91}$ que tem em sua composição nanopartículas de prata antimicrobianas que atuam na inibição do odor. Em ajuda no combate ao Covid-19, a Dublauto Gaúcha doou tecidos nanotecnológicos antimicrobianos para a confecção de calças e jalecos cirúrgicos para profissionais da saúde que estão atuando na linha de frente. Os tecidos doados também serão utilizados na fabricação de roupas de cama para hospitais. $\mathrm{O}$ projeto para o qual foi realizada a doação, é liderado pela diretoria de Inovação e do curso de Moda da Feevale e prevê a doação dos materiais aos hospitais do Vale do Rio dos Sinos. ${ }^{92}$

Além dos produtos promovidos pelas startups e empresas brasileiras, as pesquisas nas universidades seguem buscando novos caminhos e validações para nanopartículas com atividade antimicrobiana. ${ }^{93-97}$ Por exemplo, ensaios clínicos comprovaram a eficácia de um novo agente anticárie a base de nanopartículas, a Nano Silver Fluoride (NSF).$^{98} \mathrm{O}$ método de tratamento com as NFP mostrouse eficaz, simples e não invasivo. Por não requerer equipamentos dentários completos, ou um ambiente clínico, e a aplicação ser barata, o tratamento com NFP pode promover um benefício a sociedade gerando mais acesso da população aos cuidados com a saúde oral. Outro exemplo, é a pesquisa realizada pela Universidade Federal de Ouro Preto em parceria com a EMBRAPA unidade Gado de Leite. Os pesquisadores desenvolveram uma nova formulação de cloxacilina (antibiótico) nanoestruturada para administração intramamária para o tratamento de mastite estafilocócica, ${ }^{99,100}$ doenças que causam grandes prejuízos aos pecuaristas de leite em todo o mundo. A administração do antibiótico nanoestruturado mostrou-se mais eficaz do que o tratamento convencional, não apresentou efeitos adversos e não gerou resíduos químicos no leite, sugerindo ser uma ótima alternativa de fármaco. Essa formulação também foi testada contra mastite subclínica em ovelhas pela Embrapa Pecuária Sudeste, gerando resultados que apresentaram taxa de cura superior com a metade da dose do antibiótico da formulação convencional. ${ }^{101}$

Dados relacionados às publicações científicas sobre nanotecnologia no ano de 2000 a 2018 mostram que pesquisadores afiliados às instituições brasileiras publicaram 26.308 trabalhos de pesquisa referente à nanotecnologia, representando apenas $1,6 \%$ do total mundial. Mesmo atrás de países como China e Índia, a taxa de crescimento anual do Brasil é de $13 \%$, o que para Bakker ainda sim reflete um grande potencial. ${ }^{102}$ No portal StatNano, foram disponibilizados dados sobre o número de artigos de nanociência publicados por 20 países pioneiros em 2019, bem como a participação dos artigos de nanociência no total de artigos de cada país. O Brasil ocupou a $16^{\mathrm{a}}$ posição no ranking, com um total de 3.345 artigos, o que equivale a $5,49 \%$ de participação na produção mundial de conhecimento na área. A primeira colocação neste ranking é a China, com total de 74.387 artigos e, em segundo lugar, estão os EUA com 23.999 artigos. ${ }^{103}$

Para o CNPEM, ainda que a produção científica brasileira voltada à geração de conhecimento específico em nanociência e nanotecnologias em quantidade absoluta seja menor do que a produção da Comunidade Europeia ou dos EUA, elas podem ser consideradas dentro do mesmo nível de qualidade do que é produzido nestes países. ${ }^{11}$

Bem como os artigos científicos, a geração de pedidos de depósito de patentes também se torna essenciais para a divulgação de conhecimento científico e tecnológico. ${ }^{104}$ Apesar da geração de patentes não ser um indicativo de que todas invenções depositadas gerarão valor econômico ou tecnológico, ${ }^{105}$ ao analisarmos alguns pedidos depositados no banco no Instituto Nacional Da Propriedade Industrial (INPI) percebemos a potencialidade dos pesquisadores brasileiros na geração de pesquisas e produtos inovadores na área da nanotecnologia antimicrobiana (Tabela 2). ${ }^{106}$

Cabe destacar que não existe uma regulamentação acerca dos produtos à base de nanotecnologia no Brasili, ${ }^{107-109}$ o que se tem é a comercialização seguindo as leis de produtos não nanotecnológicos como a Lei $n^{\circ} 9.782$ de 1999, do Sistema Nacional de Vigilância Sanitária; ${ }^{110}$ a Lei ${ }^{\circ} 6.938$ de 1981, sobre a Política Nacional do Meio Ambiente; ${ }^{111}$ Lei $n^{\circ} 9.605$ de 1998, sobre Lei de Crimes Ambientais; ${ }^{112}$ e a Lei ${ }^{\circ} 11.105$ de 2005 , que designa normas de segurança e mecanismos de fiscalização das atividades que envolvam organismos geneticamente modificados e seus derivados. ${ }^{113}$ Os produtos com ação antimicrobiana estão subordinados à regulação da Resolução de Diretoria Colegiada - RDC $n^{\circ} 14$, de 28 de fevereiro de 2007, ${ }^{114}$ a qual é estabelecida terminologias e aplicação dos produtos, bem como é determinado a proibição de formulações que contenham substâncias que sejam comprovadamente carcinogênicas, mutagênicas e teratogênicas para o homem. Tintas com ação saneantes estão regulamentadas pela nota técnica 9/2019 da ANVISA e pela RDC 59/2010. ${ }^{115,116}$ No mais, o MCTIC disponibilizou um repositório com as normas de segurança de materiais nanotecnológicos gerados a partir dos estudos realizados no projeto NANoReg. Essas normas irão auxiliar os órgãos regulatórios na avaliação da qualidade dos materiais produzidos em escala nano, o que irá garantir maior segurança para a utilização dos nanoprodutos. ${ }^{42,117}$

\section{CONCLUSÕES}

Os nanomateriais têm se mostrado promissores para a geração de produtos em diversas aplicações. Os antimicrobianos nanoestruturados têm sido considerados como uma boa alternativa em conjunto aos ativos usuais e, devido aos ganhos em eficácia e custo-benefício, as aplicações desses materiais têm sido ampliadas para vários produtos. No Brasil, nas últimas duas décadas, houve diversas inciativas governamentais de fomento e estruturação do setor. Diversas parcerias entre empresas e instituições públicas foram estabelecidas e resultaram na formação e na consolidação de empresas nacionais e algumas delas de atuação internacional. Esse breve histórico recente da nanotecnologia brasileira evidencia a importância da continuidade dos investimentos públicos para fomentar e coordenar as pesquisas em nanotecnologia e capacitar a indústria brasileira para competição no mercado internacional. 
Tabela 2. Exemplos de pedidos de patentes no Brasil que usam nanotecnologia antimicrobiana

\begin{tabular}{cc}
\hline Título e $\mathrm{n}^{\circ}$ do pedido & Nome do depositor e dos inventores \\
\hline & Universidade de São Pão (USP) / Fundação de \\
Membrana de hidrogel e curativo & Amparo à Pesquisa do Estado de São Paulo \\
inteligente & (FAPESP) - Henrique Eisi Toma / Koiti Araki / \\
(PI0902080-2 B1) & Luíz Henrique Catalani / Renata Fogaça da Silva \\
/ Vitor de Moraes Zamarion
\end{tabular}

$\begin{array}{cc} & \\ & \\ \text { Processo de funcionalização de } & \text { Universidade Estadual de Campinas (BR/ } \\ \text { nanopartículas de prata com } & \text { Universidade Federal de São Paulo (BR/SP) } \\ \text { grupamentos S-nitrosotióis, veículo } & \text { - Amedea B. Seabra / Nelson E. D. Caballero } \\ \text { carreador de óxido nítrico (NO) e uso } & \text { / Olga R. Araneda / Maria Cristina D. Jerez } \\ \text { do veículo } & \text { / Gonzalo T. Fuentes / Nixson M. Elgueta / } \\ \text { (BR 10 2015 015357 0 A8) } & \text { Raphael Cuevas / Marconi da Cruz Santos }\end{array}$

Descrição

Estrutura composta de micro e/ou nanofibras que contém incorporados agentes ativos com forte ação bactericida, bacteriostática e fungicida na forma de NPs metálicas e enzimas proteolíticas como componentes ativos incorporados que atuam nos tecidos desvitalizados. A invenção também descreve um curativo inteligente que usa a referida membrana.

A invenção baseia-se na combinação da nanotecnologia com moléculas doadoras de NO para viabilizar seu uso terapêutico e descreve um processo de funcionalização da superfície de nanopartículas de prata biogênicas com quantidades terapêuticas de grupamentos S-nitrosotióis doadoras de NO, como veículos de liberação controlada de NO. O veículo pode ser aplicado na área biomédica e na área farmacêutica; também poder ser utilizado em revestimentos antimicrobiano de materiais médicos e tecidos, como roupas, e na área agrícola para proteção de alimentos quanto aos micro-organismos nocivos.

A referente invenção traz um valor agregado ao fio de sutura. O dito fio de sutura é constituído por fibra sintética, trançada

Universidade Federal da Paraíba (BR/PB) Isabela A. P. Farias / Fábio C. Sampaio / Carlos Christiano L. dos Santos / Jocianelle Maria F. F. Nunes / Jailson M. Ferreira / Dawy K. de Araújo Almeida / Max R. Quirino de Poliglactina 910 composta por copolímero obtido a partir ácido glicólico e L-lactida na proporção 9:1, com óxido de cério nanoparticulado obtido pelo método hidrotermal de micro-ondas adsorvido a sua superfície, a fim de estabelecer um material de sutura com reduzida aderência antimicrobiana das principais bactérias presentes no sítio de infecção, $S$. aureus e MRSA.

Obtenção de nanopartícula de fécula de cará como agente encapsulante de óleo essencial para ser inserida em uma matriz polimérica natural de baixo custo e de pureza aceitável, formando nanopartículas que devem conter efeito antimicrobiano ativo sobre o fungo causador da antracnose, além de servir como aditivo de reforço em filmes formados a base da mesma matriz polimérica, sem alterar os aspectos de cor, odor ou espessura dos filmes.

Processo de obtenção de nanopartículas a base de fécula de cará como agente encapsulante de óleo essencial, seu uso como agente antifúngico e aditivo de reforço em filme biodegradável

(BR 1020180677462 A2)

\section{Composição envolvendo nanopartículas de prata, quitosana e antibióticos com potencial antibacteriano combinado (BR 1020120273357 B1) \\ Formulação semissólida contendo nanopartículas de prata biológica e sinvastatina, processo de obtenção e uso antimicrobiano}

(BR 1020160216672 A2)
Uso farmacologico de nanopartículas ciclodextrina-Au-tiolderivadal composto hidrofóbico como antitumoral, antibacteriano, antiviral e/ou antiparasitário e seu processo de obtenção e sua formulação (PI 05026571 B1)
Universidade Federal da Paraíba (BR/PB) - Silvanda de Melo Silva / Whesley Silva de Morais / Mariany Cruz Alves da Silva / Randolph Mark Beaudry

cor, odor ou espessura dos filmes.

FAPEMIG (BR/MG) / Universidade Federal de Juiz de Fora (BR/MG) - Antônio C. Sant'ana / Claúdio G. Diniz / Vânia Lúcia da Silva / Mariana S. L. Neves / Aline L. Filgueiras

Composição que possui uma atividade antibacteriana e um potencial de aplicação no combate a bactérias Gram positivas e Gram negativas, resistentes ou que apresentem sensibilidade diminuída a antibióticos.

Universidade Estadual de Londrina / UNICAMP

- Gerson Nakazato / Renata K. T. Kobayashi /

Luciano A. Panagio / Erick K. Nishio / Karla C.

P. Bocate / Audrey A. S. G. Lonni / Nelson E.

D. Caballero/ Erica P. Figueiredo / Larissa C. de Camargo / Jhonatan M. Ribeiro

Formulação semissólida de uso tópico, na forma de um gel contendo uma mistura de sinvastatina (composto antilipidêmico) e nanopartículas de prata produzidas por ação de enzimas do fungo Fusarium oxysporum (biogênica) apresentando atividade antibacteriana e antifúngica.

Produção e formulação da violaceína encapsulada em $<225>$-ciclodextrina conjugada a uma nanopartícula de ouro por meio de um ditiol como a mono[6-deoxi-6[(mercaptohexametileno)tio] $]-<225>$-cyclodextrina-Au (Au$\mathrm{S}(\mathrm{CH} \sim 2 \sim) \sim 6 \sim-\mathrm{S}-<225>-\mathrm{CD})$ e sua citoxicidade in vitro em duas diferentes culturas de células (células leucêmicas HL60 e fibroblastos V79).

Fonte: INPI (2020).

\section{REFERÊNCIAS}

1. http://antigo.mctic.gov.br/mctic/opencms/tecnologia/tecnologias convergentes/paginas/nanotecnologia/NANOTECNOLOGIA.html, acessada em Março 2021.

2. Ferreira, H. S.; Rangel, M. C.; Quim. Nova 2009, 32, 1860

3. Schulz, P. A.; Rev. Bras. Ensino Fis. 2018, 40, 4210

4. http://www.anamt.org.br/site/upload_arquivos/legislac ao_2015_251120151338147055475.pdf, acessada em Março 2021.

5. https://editorakarywa.files.wordpress.com/2017/11/as-normas-iso-e-asnanotecnologias1.pdf, acessada em Março 2021.
6. Busquets, R; Mbundi, L. Em Emerging Nanotechnologies in Food Science; Busquets, R; Mbundi, L., eds.; Elsevier: Amsterdam, 2017, cap. 1.

7. https://www.iso.org/committee/381983/x/catalogue/, acessada em Março 2021.

8. https://ec.europa.eu/research/industrial_technologies/ $\mathrm{pdf} /$ policy/commission-recommendation-on-the-definition-ofnanomater-18102011_en.pdf, acessada em Março 2021.

9. Resch, S.; Farina, M. C.; RAM Revista de Administração Mackenzie (2015), https://doi.org/10.1590/1678-69712015/administracao. v16n3p51-75. 
10. Louro, H.; Borges, T.; Silva, M. J.; Revista Portuguesa de Saúde Pública 2013, 31, 188.

11. https://cnpem.br/wp-content/uploads/2019/10/SEPARATA-CNPEM-02_ Benef\%C3\%ADcios-e-riscos-das-nanotecnologias.pdf, acessada em Março 2021.

12. Fernandes, M. F. M.; Filgueiras, C. A. L. Quim. Nova 2008, 31, 2205.

13. Pelgrift, R.Y.; Friedman, A. J.; Adv. Drug Delivery Rev. 2013, 65, 1803.

14. https://abihpec.org.br/comunicado/setor-de-higiene-pessoal-perfumariae-cosmeticos consolida-alta-de-58-entre-os-meses-de-janeiro-esetembro-de-2020/, acessada em Março 2021.

15. https://www.who.int/news-room/fact-sheets/detail/antimicrobialresistance, acessada em Março 2021

16. Khezerlou, A.; Alizadeh- Sani, M.; Azizi-Lalabadi, M.; Ehsani, A.; Microb. Pathog. 2018, 123, 505.

17. Rice, K. M.; Ginjupalli, G. K.; Manne Nandini, D. P. K.; Jones, C. B.; Blough, E. R.; Nanotechnology (2019), DOI:10.1088/1361-6528/ ab0d38.

18. Fernando, S.; Gunasekara, T.; Holton, J.; Sri Lankan Journal of Infectious Diseases 2018, 8, 2.

19. Omolo, C. A.; Kalhapure, R. S.; Jadhav, M.; Rambharose, S.; Mocktar, C.; Ndesendo, V. M. K.; Govender, T.; Eur. J. Pharm. Bipharm. 2017, 112, 96 .

20. Hadinoto, K.; Cheow, W. S.; Colloids Surf. B 2014, 116, 772.

21. Patra, J. K.; Das, G.; Fraceto, L. F.; Campos, E. V. R.; Rodriguez-Torres, M. P.; Acosta-Torres, L. S.; Diaz-Torres, L. A.; Grillo, R.; Swamy, M. K.; Sharma, S.; Habtemariam, S.; Shin, H.; J. Nanobiotechnol. (2018), DOI:10.1186/s12951-018-0392-8.

22. https://www.nano.gov/about-nni, acessada em 22 de julho de 2020.

23. Ferreira, V. B. Em E-science e políticas públicas para ciência, tecnologia e inovação no Brasil [online], EDUFBA: Salvador, 2018, pp. 97-106.

24. Plents, F.; Fazzio, A.; Cienc. Cult. (Campinas, Braz.) (2013) DOI:10.21800/S0009-67252013000300010.

25. https://antigo.mctic.gov.br/mctic/opencms/legislacao/portarias/ migracao/Portaria_MCT_n_252_de_16052003.html, acessada em Março 2021.

26. https://antigo.mctic.gov.br/mctic/opencms/legislacao/portarias/migracao/ Portaria_MCT_n_614_de_01122004.html, acessada em Março 2021.

27. https://www2.camara.leg.br/orcamento-da-uniao/leis-orcamentarias/ ppa/2004-2007/avalia2005/vol1/voli_02ciencia.pdf, acessada em Março 2021.

28. https://www2.camara.leg.br/orcamento-da-uniao/leis-orcamentarias/ ppa/2004-2007/avalia2005/vol1/voli_02ciencia.pdf, acessada em Março 2021.

29. https://livroaberto.ibict.br/bitstream/1/676/4/Plano $\% 20$ de $\% 20$ A\%c3\%a7\%c3\%a3o\%20em\%20Ci\%c3\%aancia\%2c\%20Tecnologia\%20 e\%20Inova\%c3\%a7\%c3\%a3o_principais\%20resultados\%20e\%20 avan\%c3\%a7os_2007-2010.pdf, acessada em Março 2021.

30. https://antigo.mctic.gov.br/mctic/opencms/legislacao/portarias/migracao/ Portaria_MCT_n_429_de_17072008.html?searchRef=fapesc\&tipoBusc $a=$ expressaoExata, acessada em Março 2021.

31. https://www.mctic.gov.br/mctic/opencms/legislacao/portarias/migracao/ Portaria_MCT_n_429_de_17072008.html, acessada em Março 2021.

32. http://inct.cnpq.br/sobre, acessada em Março 2021.

33. http://estatico.cnpq.br/programas/inct/_apresentacao/docs/livro2013.pdf, acessada em Março 2021.

34. Ferreira, V. B. Em E-science e políticas públicas para ciência, tecnologia e inovação no Brasil [online], EDUFBA: Salvador, 2018 , pp. 107.

35. http://www.comexresponde.gov.br/portalmdic//sitio/interna/interna. php?area $=3 \&$ menu $=2469 \&$ refr $=2764$, acessada em Março 2021.

36. https://www.camara.leg.br/proposicoesWeb/prop_mostrarintegra;jsess ionid=65D91EAB7FA3527D6F0A74E404527951.proposicoesWebEx terno1?codteor $=1759487 \&$ filename $=\mathrm{MCN}+6 / 2019+\mathrm{CN}$, acessada $\mathrm{em}$ Março 2021

37. https://confap.org.br/news/mctic-e-cnpq-lancam-chamada-dosisnano-2-0/, acessada em Março 2021.

38. https://antigo.mctic.gov.br/mctic/export/sites/institucional/tecnologia/ incentivo_desenvolvimento/sisnano/arquivo-sisnano/PDF-7-FolderSisNANO-2.0.pdf, acessada em Março 2021.

39. https://antigo.mctic.gov.br/mctic/export/sites/institucional/tecnologia/ incentivo_desenvolvimento/sisnano/arquivo-sisnano/PDF-4-PortariaMCTIC-2376-Sisnano-Atualizado.pdf, acessada em Março 2021.

40. https://antigo.mctic.gov.br/mctic/export/sites/institucional/tecnologia/ tecnologiasSetoriais/Plano-de-Acao-em-CTI_Nanotecnologia_FINAL. pdf, acessada em Março 2021.

41. https://www.in.gov.br/web/dou/-/portaria-n-3.459-de-26-de-julhode-2019-209514505, acessada em Março 2021.

42. https://www.rivm.nl/en/about-rivm/mission-and-strategy/internationalaffairs/international-projects/nanoreg, acessada em Março 2021.

43. https://antigo.mctic.gov.br/mctic/opencms/legislacao/portarias/Portaria_ MCTIC_n_324_de_17012018.html, acessada em Março 2021.

44. https://cnpem.br/ciencia-brasil-inaugura-o-sirius-o-maior-acelerador-departiculas-de-luz-sincrotron-do-mundo/, acessada em Março 2021.

45. http://cnpem.br/portfolio-item/video-sirius/, acessada em Março 2021.

46. https://antigo.mctic.gov.br/mctic/opencms/salaImprensa/noticias/ arquivos/2018/10/MCTIC_lanca_plano_de_acao_para_o_ desenvolvimento_da_nanotecnologia_e_da_industria_40_no_Brasil. html?searchRef=tecnologias $\% 20$ convergentes $\% 20 \mathrm{e} \% 20$ habilitadoras \&tipoBusca=expressaoExata, acessada em Março 2021.

47. https://www12.senado.leg.br/noticias/materias/2020/02/19/marco-legalda-nanotecnologia-avanca, acessada em Março 2021.

48. https://www.in.gov.br/web/dou/-/portaria-n-1.122-de-19-de-marcode-2020-249437397, acessada em Março 2021.

49. https://www.congressonacional.leg.br/materias/materias-orcamentarias/ pldo-2020, acessada em Março 2021

50. https://www.researchandmarkets.com/reports/5143395/antimicrobialtextile-market-by-active-agents?utm_source=GNOM\&utm medium $=$ PressRelease\&utm_code $=2 \mathrm{~g} 58$ sr\&utm_campaign $=1437244+$ +Global+Antimicrobial+Textile+Markets+to+2025\%3a+Massive+U se+of+Antimicrobial+Textiles+in+Hospitals\&utm_exec=chdo54prd, acessada em Março 2021

51. https://www.marketsandmarkets.com/Market-Reports/antimicrobialplastic-market-20591555.html\#: :text=\%5B 171\%20Pages $\% 20$ Report\%5D\%20The\%20antimicrobial,at\%20a\%20CAGR\%20of\%20 $10.1 \% 25 . \&$ text $=$ Growing $\% 20$ demand $\% 20$ for $\% 20$ antimicrobial $\% 20$ plastics,various \%20opportunities\%20for\%20the \%20manufacturers, acessada em Março 2021

52. Wang, L. L.; Hu. C.; Shao, L. Q.; Int J Nanomed. 2017, 12, 1227.

53. Bethy, N.; Houri-Haddad, Y.; Domb, A.; Khan, W.; Hazan, R.; $J$. Evidence-Based Complementary Altern. Med. 2015, 2015, 246012

54. Hoseinzadeh, E.; Makhdoumi, P.; Taha, P.; Hossini, H.; Stelling, J.; Kamal, M. A.; Ashraf, G. M.; Curr Drug Metab. 2017, 18, 120.

55. http://www.nanox.com.br, acessada em Março 2021

56. https://www.alpfilm.com.br/como-funciona-o-escudo-de-protecaoantibacteriana-da-alpfilm/, acessada em Março 2021.

57. https://revistapesquisa.fapesp.br/inovacao-em-pequena-escala/, acessada em Março 2021

58. https://anpei.org.br/nanox-cria-bactericida-e-investe-em-exportacao/, acessada em Março 2021

59. https://www.pequenochic.com.br/produtos/dental-bone-odontopetargola-com-sabor-ate-15kg/, acessada em Março 2021.

60. https://www.quimica.com.br/incubadoras-entidades-ajudam-empresas-dealta-tecnologia-a-dar-seus-primeiros-passos/4/, acessada em Março 2021.

61. https://www.termolar.com.br/garrafa-termica-minigarbo-branca-250mlrolha-clean, acessada em Março 2021. 
62. https://www.otomask.com.br/, acessada em Março 2021.

63. https://tnsolution.com.br/, acessada em Março 2021.

64. https://www.ulprospector.com/pt/la/Coatings/Detail/33586/722856/ NpAg_925, acessada em Março 2021.

65. https://tnsolution.com.br/nanoparticula-tns-apresenta-atividadeantiviral/, acessada em Março 2021.

66. http://www.panelasoxford.com.br/, acessada em Março 2021.

67. ht tps:// d 3351 u u pugs 2 . cloudfront.net/c m s / files/4325/1555944512Ebook_Yuze_TNS.pdf, acessada em Março 2021.

68. https://bold.net/chapa/acrilico-bold-nanopower/, acessada em Março 2021.

69. https://noticias.portaldaindustria.com.br/noticias/inovacao-e-tecnologia/ video-esse-spray-torna-as-superficies-a-prova-do-coronavirus/, acessada em Março 2021.

70. https://www.nanovetores.com.br/, acessada em Março 2021.

71. https://www.nanovetores.com.br/nano-fungi, acessada em Março 2021.

72. https://www.nanovetores.com.br/post/junto-com-o-\%C3\%A1lcool-gelchegou-o-tempo-da-hidrata\%C3\%A7\%C3\%A3o, acessada em Março 2021.

73. https://podalnanocosmeticos.com.br/, acessada em Março 2021.

74. https://podalnanocosmeticos.com.br/loja/nano-cosmeticos/para-a-pele/ fungi-mai-auxiliar-na-eliminacao-de-fungos, acessada em Março 2021.

75. https://www.doceerva.com.br/nano-nails-liquido-10ml-frasco-compincel-p503/, acessada em Março 2021.

76. https://www.nanoscoping.com.br/, acessada em Março 2021.

77. http://www.invencoesbrasileiras.com.br/ceramica-bactericida/, acessada em Março 2021.

78. http://www.innoma.com.br/, acessada em Março 2021.

79. Oliveira, D.S.; Ferreira, T.H.; BR 102020000325 9, 2020.

80. https://comunidade.startse.com/in/nanotropic, acessada em Março 2021.

81. https://nanowear.com.br/tecidos-inteligentes/, acessada em Março 2021.

82. https://revistapesquisa.fapesp.br/2006/12/01/tecidos-funcionais/, acessada em Março 2021.

83. https://www.weg.net/tomadas/blog/tecnologia/protecao-antimicrobianae-antiviral-em-tomadas-e-interruptores/, acessada em Março 2021.

84. https://revistapesquisa.fapesp.br/2007/06/01/multiplas-utilidades/, acessada em Março 2021.

85. https://protectedbylanxess.com.br/fileadmin/user_upload/Brochura_ TINTAS_IPEL_2017_INGLES_WEB.pdf, acessada em Março 2021.

86. http://laza.bio.br/produto/5-full-clean, acessada em Março 2021

87. https://loja.promaflex.com.br/antimofo-bactericida-manta- $2 \mathrm{~mm}$, acessada em Março 2021.

88. https://equinox.com.br/camiseta-ion-lite-feminina-solo.html, acessada em Março 2021

89. https://www.insiderstore.com.br/, acessada em Março 2021.

90. http://gaucha.dublauto.com.br/produtos/5/LinhaTecnolA\%EF\%BF\%BDgica---Tratamentos, acessada em Março 2021.

91. http://gaucha.dublauto.com.br/noticias/2018/05/53/Oportunidadestrazidas-pelo-uso-da-nanotecnologia-na-indA\%EF\%BF\%BDstria, acessada em Março 2021.

92. http://www.assespro-rs.org.br/roupas-com-nanotecnologia-podemaumentar-protecao-nos-hospitais/, acessada em Março 2021.

93. Rodrigues, A. G.; Ping, L. Y.; Marcato, P. D.; Alves, O. L.; Silva, M. C. P.; Ruiz, R. C.; Melo, I. S.; Tasic, L.; de Souza, A. O.; Appl. Microbiol. Biotechnol. 2013, 97, 775.
94. Andre, R. S.; Zamperini, C. A.; Mima, E. G.; Longo, V. M.; Alburqueque, A. R.; Sambrano, J. R.; Machado, A. L.; Vergani, C. E.; Hernandes, A. C.; Varela, J. A.; Longo, E.; Chem. Phys. 2015, 459, 87.

95. De Oliveira, J. F. A.; Saito, A.; Bido, A. T.; Kobarg, J.; Stassen, H. K.; Cardoso, M. B.; Sci. Rep. 2017, 7, 1326.

96. Dutra-Correa, M.; Leite, A. A. B. V.; de Cara, S. P. H. M.; Diniz, I. M. A.; Marques, M. M.; Suffredini, I. B.; Fernandes, M. S.; Toma, S. H.; Araki, K.; Medeiros, I.; Journal of Dentistry 2018, 77, 66.

97. Rodrigues, C.; de Mello, J. M. M.; Dalcanton, F.; Macuvele, D. L. P.; Padoin, N.; Fiori, M. A.; Soares, C.; Riella, H. G.; J. Polym. Environ. 2020, 28, 1216.

98. Santos Jr., V. E.; Filho, A. V.; Targino, A. G. R.; Flores, M. A. P.; Galembeck, A.; Caldas Jr., A. F., Rosenblatt, A.; Journal of Dentistry 2014, $42,945$.

99. https://ufop.br/noticias/pesquisa-e-inovacao/ufop-cria-medicamentopara-combater-mastite-bovina, acessada em Março 2021.

100. Mosqueira, V. C. F.; Araújo, R. S.; Brandão, H.; PCT/BR2011/000168, 2011.

101. https://www.embrapa.br/busca-de-noticias/-/noticia/18708181/cavalode-troia-contra-a-mastite-bovina, acessada em Março 2021.

102. https://www.rvo.nl/sites/default/files/2019/07/Nanotechnologyinnovation-in-Brazil-a-macro-analysis.pdf, acessada em Março 2021.

103. https://statnano.com/news/67470/2019\%E2\%80\%99s-20-LeadingCountries-in-Nanotechnology-Publications, acessada em Março 2021.

104. Mueller, S. P. M.; Perucchi, V.; Perspectivas em Ciência da Informação 2014, 19, 15 .

105. Sant'anna, L. S.; Alencar, M. S. M.; Ferreira, A. P.; Quim. Nova 2013, 36,348 .

106. http://www.inpe.br/, acessada 22 de julho de 2020.

107. Ferreira, A. P.; Sant'anna, L. S.; Revista UNIANDRADE, 2015, 16, 119.

108. Lazzaretti, L. L.; Hupffer, H. M.; Revista Gestão e Desenvolvimento 2019, 16, 153.

109. http://sectordialogues.org/sites/default/files/acoes/documentos/dialogos_ setoriais_-_nanotecnologia_portugues.pdf, acessada em Março 2021.

110. http://www.planalto.gov.br/ccivil_03/leis/L9782.htm, acessada em Março 2021.

111. http://www.planalto.gov.br/ccivil_03/LEIS/L6938.htm, acessada em Março 2021.

112. http://www.planalto.gov.br/ccivil_03/leis/19605.htm, acessada em Março 2021.

113. http://www.planalto.gov.br/ccivil_03/_ato2004-2006/2005/lei/ 111105.htm\#: :text=1\%C2\%BA\%20Esta\%20Lei\%20estabelece\%20 normas,o\%20descarte $\% 20 \mathrm{de} \% 20$ organismos $\% 20$ geneticamente, acessada em Março 2021.

114. https://www.cevs.rs.gov.br/upload/arquivos/201611/08140937rdc-14-2007.pdf, acessada em Março 2021.

115. https://www.gov.br/anvisa/pt-br/setorregulado/regularizacao/cosmeticos/ notas-tecnicas/nota-tecnica-no-9-2019-sei-ghcos-dire3-anvisa.pdf/view, acessada em Março 2021.

116. https://www.normasbrasil.com.br/norma/resolucao-3169-2006_102859. html, acessada em Março 2021.

117.https://antigo.mctic.gov.br/mctic/opencms/salaImprensa/ noticias/arquivos/2018/09/MCTIC_organiza_repositorio_com_ procedimentos_e_regras_para_produtos_nanotecnologicos.html?searc $\mathrm{hRef}=$ nanosseguran\%C3\%A7a\&tipoBusca=expressaoExata, acessada em Março 2021. 